\title{
Coronary Artery Reperfusion
}

\author{
II. REDUCTION OF MYOCARDIAL INFARCT SIZE AT \\ 1 WEEK AFTER THE CORONARY OCCLUSION
}

\author{
W. R. Ginks, H. D. Sybers, P. R. Maroko, J. W. Covell, B. E. Sobel, and \\ J. Ross, JR. \\ From the Department of Medicine, University of California, San Diego, \\ School of Medicine, La Jolla, California 92037
}

A B S T R A C T The question of whether or not the size of an area of myocardial infarction, measured at $1 \mathrm{wk}$ after coronary occlusion, can be influenced by coronary artery reperfusion was examined in dogs. In seven control experiments the anterior descending coronary artery was ligated, while in seven other studies the occlusion was released after $3 \mathrm{hr}$. In all animals calibrated photographs were used to assess the zone of hypoperfusion and the acutely injured area of epicardial ST segment elevation, as well as the extent of damage at postmortem $1 \mathrm{wk}$ later. In control dogs, the gross infarct size at postmortem averaged $63.8 \pm 7.3 \%$ of that predicted from the acutely injured zone. However, in reperfused hearts the average gross infarct size at 1 wk was only $10.2 \pm 4.4 \%$ of that predicted. Transmural specimens were obtained at autopsy for histology and measurement of myocardial creatine phosphokinase (CPK) activity from sites initially used for epicardial electrocardiography. In control animals, there was a direct relationship between the degree of ST segment elevation and the degree of cell necrosis in transmural histologic sections. ST segment elevation also predicted myocardial CPK (international units per milligram protein) : $\log \mathrm{CPK}=-0.0613 \mathrm{ST}+1.17(r=$ $0.66, \mathrm{n}=56$ sites). In the reperfused animals, $\log$ $\mathrm{CPK}=-0.166 \mathrm{ST}+1.36 \quad(r=0.69, \mathrm{n}=46$ sites $)$ showing almost complete preservation of CPK activity at $1 \mathrm{wk}$, sparing being most prominent in the epicardial zone. Similarly, there was a good correlation between myocardial CPK activity and the histological assessment of cell destruction, the degree of cell damage $=$ $-0.152 \mathrm{CPK}+3.86(r=0.86 ; \mathrm{n}=102$ sites $)$. Thus, control dogs showed severe myocardial CPK depletion

Received for publication 3 April 1972 and in revised form 30 June 1972. and histologic evidence of extensive cell destruction, whereas animals subjected to coronary artery reperfusion had little CPK depletion and much less evidence of myocardial cell necrosis 1 wk later.

\section{INTRODUCTION}

In the recent past, a more complete understanding of the determinants of myocardial oxygen consumption has become available (1) and their relevance to acute myocardial infarction assessed. Several factors which influence myocardial oxygen demand have been shown to alter the extent of myocardial infarction (2). It also has been contended that increasing the supply of oxygen to the myocardium by means of coronary artery bypass may limit the extent of myocardial infarction in patients $(3,4)$; however, so far there is no direct experimental or clinical evidence that reestablishment of blood supply through a previously occluded coronary artery can influence the extent of subsequent myocardial necrosis. In the accompanying study, coronary artery reperfusion was shown by previously established techniques to improve immediate contractile function and to limit the extent of early myocardial ischemic injury at $24 \mathrm{hr}$ (5).

In this study, a method for detecting differences in myocardial infarct size late after coronary occlusion was developed and employed to determine whether or not coronary artery reperfusion after a $3 \mathrm{hr}$ period of temporary occlusion can alter the extent of myocardial infarction assessed $1 \mathrm{wk}$ later.

\section{METHODS}

Studies were carried out in 14 mongrel dogs weighing between 16 and $34 \mathrm{~kg}$, anesthetized with intravenous sodium thioamylal (25 mg/kg). Respiration was maintained through 


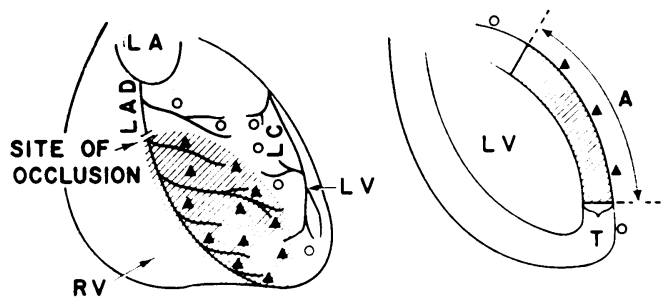

Figure 1 Left panel: schematic representation of the anterior surface of the heart. The coronary arteries and branches and sites of epicardial electrocardiograms are marked. $\bigcirc$, normal ST segment ; $\boldsymbol{\Delta}$, abnormal ST segment. The cross-hatched area represents the area of acute injury 15-30 min after occlusion. $\mathrm{LV}$, left ventricle; $\mathrm{RV}$, right ventricle; LA, left atrial appendage; LAD, left anterior descending coronary artery; LC, left circumflex coronary artery. Right pancl: sagittal section of the left ventricle indicating the volume of acute myocardial injury; A, surface area of injury determined by epicardial electrocardiography and $T$, left ventricular wall thickness.

an endotracheal tube attached to a Harvard respirator (Harvard Apparatus Co., Millis, Mass.) and the animals were ventilated with room air. In each experiment, the heart was exposed through an incision in the fifth left intercostal space and suspended in a pericardial cradle. The left anterior descending coronary artery (LAD) ${ }^{1}$ was carefully dissected free of its accompanying venae comitans at a site usually above the apical branch of the LAD. In seven animals, the artery was occluded temporarily for a period of $3 \mathrm{hr}$ with a Schwartz arterial clamp (Pilling Surgical Instruments, Fort Washington, $\mathrm{Pa}$.), while in seven control dogs the artery was permanently ligated (5). Because variable tissue damage was noted in dogs requiring electrical countershock, both control and reperfused animals in which ventricular fibrillation occurred were excluded from the analysis.

Approximately 15 sites on the anterior surface of the left ventricle were selected for epicardial electrocardiography (2), in order to determine the extent of acute myocardial ischemic injury. Epicardial electrocardiograms were obtained in every experiment before occlusion and $5,10,15$ : 30,90 , and $180 \mathrm{~min}$ after occlusion. Since the recordings obtained from each specified epicardial site were repeated, sites were selected near the bifurcation of arteries or veins so that the recording probe could easily be repositioned at the same location (Fig. 1).

The ST segment elevation at each site was used as an index of the severity of local myocardial injury. The sites at which myocardial ischemic injury was considered to exist were those where ST segment elevation exceeded $2 \mathrm{mv}$. An area of myocardial injury was then determined by transposing the abnormal epicardial sites to a calibrated photograph of the heart in situ. A grid was photographed at the same distance as the heart and the involved area measured by planimetry.

The surface area of acute myocardial injury was also determined by two additional methods. After occlusion of the artery, part of the antero-apical surface of the left ventricle became cyanotic within 5-30 sec and the involved

${ }^{1}$ Abbreviations used in this paper: $\mathrm{CPK}$, creatine phosphokinase; GOT, glutamic oxaloacetic transaminase; LAD, left anterior descending coronary artery; LDH, lactate dehydrogenase; $\mathrm{SDH}$, succinic dehydrogenase. area of myocardium appeared to cease contracting. In initial experiments, the area of hypoperfusion was shown by color photographs after left atrial injection of $10 \mathrm{ml}$ of $4 \%$ buffered methylene blue solution. In a number of these animals, the experiment was later terminated acutely because of ventricular fibrillation. In other experiments, color photographs were taken of the area of cyanosis on the surface of the left ventricle. The volume of acute cellular damage was then estimated as the product of the area of myocardial injury and average left ventricular wall thickness, the latter being measured at autopsy from calibrated photographs (Fig. 1).

In all experiments, arterial pressure was monitored throughout the procedure by means of a Statham pressure transducer (Statham Instruments, Inc., Oxnard, Calif., model $\mathrm{P} 23 \mathrm{Db}$ ) and recorded together with standard electrocardiographic leads and the epicardial electrocardiogram on a Clevite Brush oscillograph (Clevite Corporation, Gould, Inc., Cleveland, Ohio).

During the week of the experiment all animals were restricted in caged quarters. 1 wk later after anesthesia and thoracotomy the animals were killed by rapid excision of the heart. In each study, the heart was weighed and cut into parallel slices. The slices were made perpendicular to the apex to base axis and each slice was approximately 10 $\mathrm{mm}$ thick. Color photographs were taken of the upper and lower surfaces of each slice, and the area of infarction was measured by planimetry, each photograph being calibrated by means of a standard reference grid. The volume of infarcted tissue within each slice then was determined as the product of the mean area of infarction and slice thickness.

Myocardial specimens also were obtained for determination of myocardial creatine phosphokinase (CPK) activity and for histological examination at the same sites at which epicardial mapping had been recorded 1 wk earlier. CPK activity was measured as described by Kjekshus and Sobel (6) and expressed as international units per milligram protein (5). Transmural sections obtained for histology were fixed in $10 \%$ formalin and stained with hematoxylin and eosin. One complete transmural section from each block was examined microscopically by an independent observer who was unaware of the relation between sample sites and the experimental protocol.

Since an infarct of 1 wk's duration contains early reparative processes as well as degenerative changes, the criteria used for determining the extent of infarction in any given transmural specimen included: $(a)$ the presence of granulation tissue; (b) loss of cross striations; $(c)$ karyorrhexis ; (d) karyolysis. The extent of infarction was graded (0 to $++++)$ depending on the estimate of the relative amounts of normal and infarcted tissue in each transmural specimen: 0 , no infarct, + , less than $25 \%$ infarction;,$++ 25-50 \%$ infarction;,$+++ \quad 50-75 \%$ infarction;,$++++ \quad 75-100 \%$ infarction.

\section{RESULTS}

\section{Acute myocardial infarct size and size at $1 \mathrm{wk}$}

In all experiments the area of acute myocardial injury after coronary occlusion was delineated by means of epicardial mapping, and the area of hypoperfusion was assessed by calibrated photography (Fig. 1). In initial experiments, a good correlation was found between the area of hypoperfusion as demonstrated by left atrial injection of methylene blue, and the area of 
cellular injury estimated by the abnormal epicardial electrocardiogram (Fig. 2). A similar relationship was found between the area of cyanosis and the area of cellular injury assessed by epicardial mapping (Fig. 2).

Control animals. At postmortem at 1 wk in control dogs, myocardial infarction was characterized in every instance by a large, well defined hemorrhagic area of necrotic tissue which was dominantly subendocardial in situation but which in each case extended transmurally to the epicardium at several points. This hemorrhagic region was bordered by a less well defined gray zone of granulation tissue which, in turn, was surrounded by normal appearing myocardium. The anatomic infarct size, defined by the area of hemorrhagic necrosis, was measured by the planimetric method described earlier. The volume of infarction measured by this anatomical examination was then expressed as a percentage of the volume of acute infarction as estimated by epicardial electrocardiography. In the control animals, anatomic infarct size ranged from 8 to $21 \mathrm{~cm}^{3}$ and averaged $63.8 \pm 7.3 \%$ SEM of that predicted from the acutely injured area (Table I).

Reperfused animals. A difference in the gross appearance of the sliced heart specimens was readily apparent between control and reperfused animals. There was no evidence of hemorrhagic infarction in four of the reperfused dogs, and in the other three animals only very small areas of hemorrhagic infarction were evident. In reperfused animals, the gray zone of granulation tissue, although present, was less readily distinguished from normal tissue than in control dogs. In reperfused dogs, the average infarct size at 1 wk was only $10.2 \pm 4.4 \%$ of that predicted acutely (Table I). The difference between the percentage decreases in

TABLE I

Myocardial Infarct Size before and after Coronary Reperfusion Compared with Controls

\begin{tabular}{lcccc}
\hline & $\begin{array}{c}\text { Average } \\
\text { ST } \\
\text { segment } \\
\text { elevation }\end{array}$ & $\begin{array}{c}\text { Average } \\
\text { acute } \\
\text { infarct } \\
\text { size }\end{array}$ & $\begin{array}{c}\text { Average } \\
\text { infarct } \\
\text { size } \\
\text { at } 1 \text { wk }\end{array}$ & $\begin{array}{c}\text { Average } \\
\text { 1 wk } \\
\text { infarct } \\
\text { size }\end{array}$ \\
\hline Controls & $m v$ & $\%$ heart wt & \% heart wt & $\begin{array}{c}\text { \% predicted } \\
\text { Reperfusions }\end{array}$ \\
\hline
\end{tabular}

The average degree of ST segment elevation is used as an index of tissue injury. Infarct size is expressed as a percentage of total heart weight (conversion to percentage of left ventricular weight can be made by multiplying by a factor of 1.53). The degree of tissue injury and size of the acute infarction was similar in both groups of animals. At 1 wk there is a striking reduction in infarct size in reperfused dogs, the average infarct size after coronary reperfusion being $85 \%$ less than in animals where the vessel remained occluded.

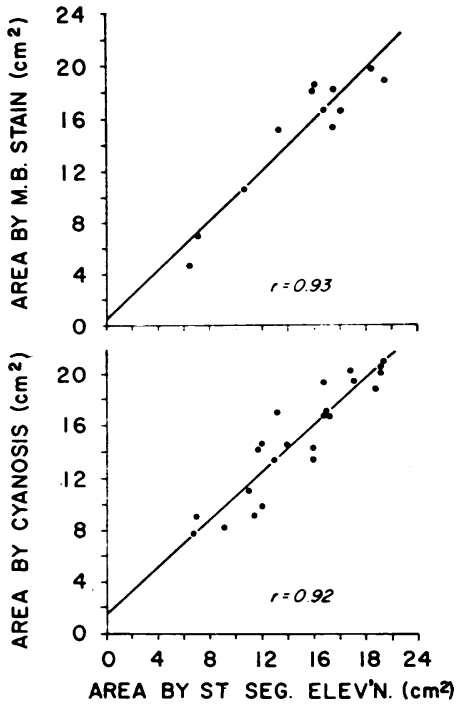

Figure 2 Comparison of the methods used to determine the area of acute myocardial injury. Upper panel: Surface area of injury as determined by epicardial mapping compared with the area of hypoperfusion estimated after left atrial injection of methylene blue (M.B.) solution. (M.B. $=0.9577 \mathrm{ST}+0.5667 ; r=0.93 ; \mathrm{n}=12)$. Lower panel: Surface area of injury as determined by epicardial mapping compared with the area of epicardial cyanosis $(\mathrm{Cy})$. (Cy $=0.8855 \mathrm{ST}+1.747 ; r=0.92 ; \mathrm{n}=23$.

acute infarct size and infarct size measured at $1 \mathrm{wk}$ in control and reperfused animals was highly significant $(P<0.01)$.

\section{Histologic studies}

Histologic studies were carried out in 56 samples from seven dogs in the control group and in 46 samples from seven dogs in the reperfused group.

Microscopic examination of control specimens revealed a large central zone of necrosis surrounded by a dense layer of granulation tissue. Many of the myocytes in the central zone retained their cross striations but had undergone karyolysis. The endocardial onethird of the myocardium was extensively involved in all instances, but frequently the central necrotic region extended into the outer one-third of the myocardium as well. A zone of granulation tissue composed of densely packed, elongated nuclei of fibroblasts and endothelial elements formed a dense band around the central necrotic zone. Numerous pyknotic neutrophils extended inward from the granulation tissue to the peripheral regions of the central necrotic zone and frequently extended deeply into its middle regions. Occasionally the outer edge of the granulation zone had a scalloped appearance, with foci of fibrous tissue alternating with normal muscle. 
In several of the reperfused animals no central zone of necrosis could be identified on histologic examination. When present, the central necrotic zone was small, confined to the endocardial one-third of the myocardium, and like the control group composed of myocytes which had retained cross striations but undergone karyloysis. A zone of granulation tissue similar to that in the control experiments surrounded such central areas of necrosis; however, only a few isolated pyknotic neutrophils extended into the necrotic zone in contrast to their frequent occurrence in the control group. The layer of granulation tissue rarely extended into the outer half of the myocardium even in transmural specimens taken from the center of the infarcted region. The outer two-thirds of the myocardium contained small foci of fibrous tissue separated by myocyctes which appeared normal, or showed some myofibrillar degenerative changes.

As shown in Fig. 3, in control animals there was a relationship between the degree of ST segment elevation and histologic assessment of cell necrosis, the degree of ST segment elevation predicting the extent of cell damage. In reperfused hearts, for a given degree of ST segment elevation there was much less evidence of tissue necrosis compared with the control experiments (Fig. 3).

\section{Myocardial CPK levels}

A direct relationship existed between the histological assessment of cell destruction and myocardial CPK activity in each transmural biopsy (Fig. 4). In control animals there was depletion of CPK activity and extensive cell necrosis, whereas in the reperfused group,

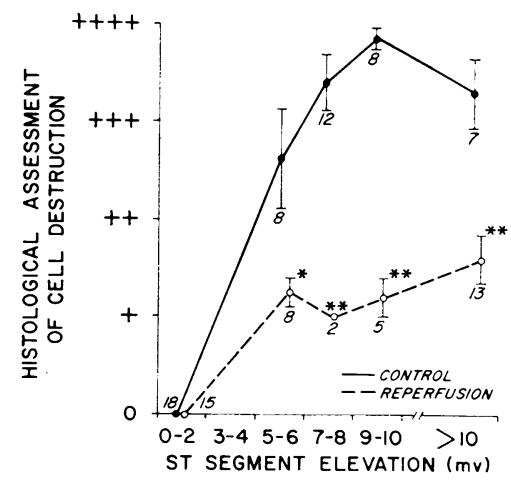

FIgUre 3 Comparison between ST segment elevation 15 min after occlusion and the histological assessment of cell destruction at the same sites 1 wk later in controls (solid upper line) and in reperfused hearts (broken lower line). The numbers next to each symbol represent the number of specimens at each level of ST segment elevation. The difference between controls and reperfusions at any given ST segment elevation is statistically significant $(* P<0.05$, $* * P<0.01)$.

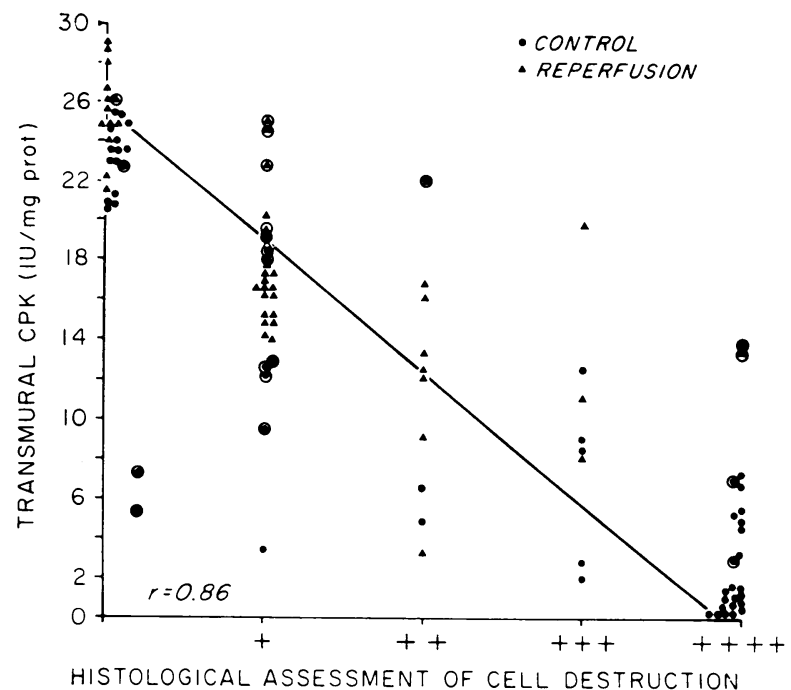

Figure 4 Comparison of data obtained from both control and reperfused dogs between the histological assessment of cell necrosis and transmural $\mathrm{CPK}$ activity (histology = $-0.1516 \mathrm{CPK}+3.859 ; r=0.86 ; \mathrm{n}=102$ ), where histology is expressed in arbitrary units as described in the text and $\mathrm{CPK}$ is measured in international units per milligram protein. In control animals (closed circles), most of the samples taken from sites that were abnormal by epicardial mapping $15 \mathrm{~min}$ after occlusion showed almost complete depletion of $\mathrm{CPK}$ activity associated with more than $75 \%$ cell destruction $(++++) 1 \mathrm{wk}$ later. In the reperfused group (closed triangles), most samples taken from sites predicted to be abnormal by ST segment elevation showed near normal CPK activity with only about $25 \%$ cell destruction in the transmural biopsy. Encircled symbols, showing considerable scatter, represent samples taken from border zones of the infarct.

tissue sparing was evidenced by near normal CPK activities and much more limited cell destruction.

Myocardial tissue salvage in the reperfused animals also was expressed by comparing the degree of ST segment elevation 15 min after coronary occlusion and myocardial CPK activity at the same sites 1 wk later. It was shown that for any given abnormal degree of ST segment elevation, myocardial CPK activity remained significantly higher in reperfused dogs than in control animals (Fig. 5), and the difference between the respective correlation coefficients was highly significant $(P<0.001)$ (Fig. 6).

On the basis of histological examination tissue sparing in reperfused hearts appeared to occur primarily toward the epicardial surface. In order to examine further the distribution of tissue damage, CPK determinations were made in the endocardial and epicardial portions of each transmural specimen obtained from areas of acute injury. In control dogs, the average epicardial and endocardial CPK activity was $5.3 \pm 0.9 \mathrm{IU} /$ $\mathrm{mg}$ and $2.6 \pm 0.8 \mathrm{IU} / \mathrm{mg}$, respectively. In contrast, in 
reperfused animals, the mean epicardial CPK activity was $18.7 \pm 0.9 \mathrm{IU} / \mathrm{mg}$ and the average endocardial $\mathrm{CPK}$ activity was $10.5 \pm 0.9 \mathrm{IU} / \mathrm{mg}$. The difference between epicardial and endocardial CPK activity was significantly greater in treated compared with control animals, $P<0.01$ (Fig. 7).

\section{DISCUSSION}

It is recognized that ischemic injury to the myocardium initially causes potentially reversible cellular changes, which then gradually become permanent as unrelieved ischemia progresses to cell death. However, the interval between the onset of coronary occlusion and the time at which myocardial tissue injury is no longer reversible has been the subject of much investigation, and the question of whether or not the degree of tissue necrosis is altered after varying periods of transient coronary occlusion has not been resolved.

In 1941, Blumgart, Gilligan, and Schlesinger (7) on the basis of light microscopic studies described myocardial infarction in dogs killed 1 wk after a transient period of coronary occlusion of $25-45 \mathrm{~min}$ duration. These authors were able to demonstrate that the extent of the infarction was approximately proportional to the duration of such temporary obstruction. Similar observations subsequently were made by several groups of investigators (8-10). In other experiments Sommers and Jennings (10) and Jennings, Kaltenbach, and Smetters (11) using biochemical markers of cellular injury, demonstrated a fall in myocardial tissue levels of GOT, LDH, and SDH to $30-50 \%$ of normal values by $12-15 \mathrm{hr}$ after permanent coronary artery ligation,

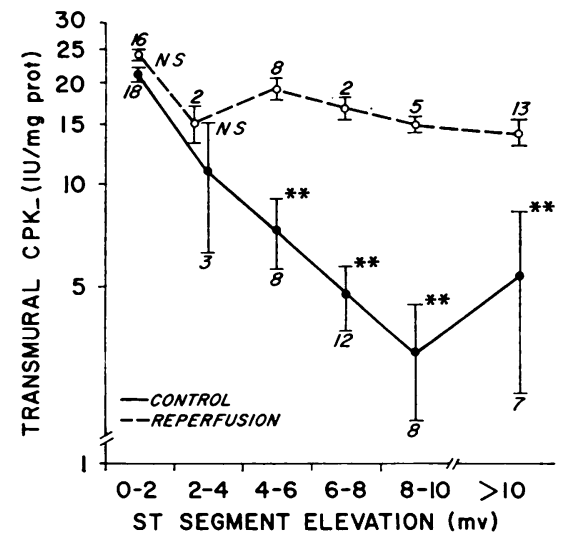

Figure 5 Comparison between ST segment elevation 15 min after occlusion and CPK activity (expressed on a logarithmic scale) obtained at the same site 1 wk later in control dogs (solid lower line) and in reperfused hearts (broken upper line). The numbers next to each symbol represent the number of specimens at each level of ST segment elevation. The difference between controls and reperfusions at any given ST segment elevation is statistically significant $(* P<0.05, * * P<0.01)$.

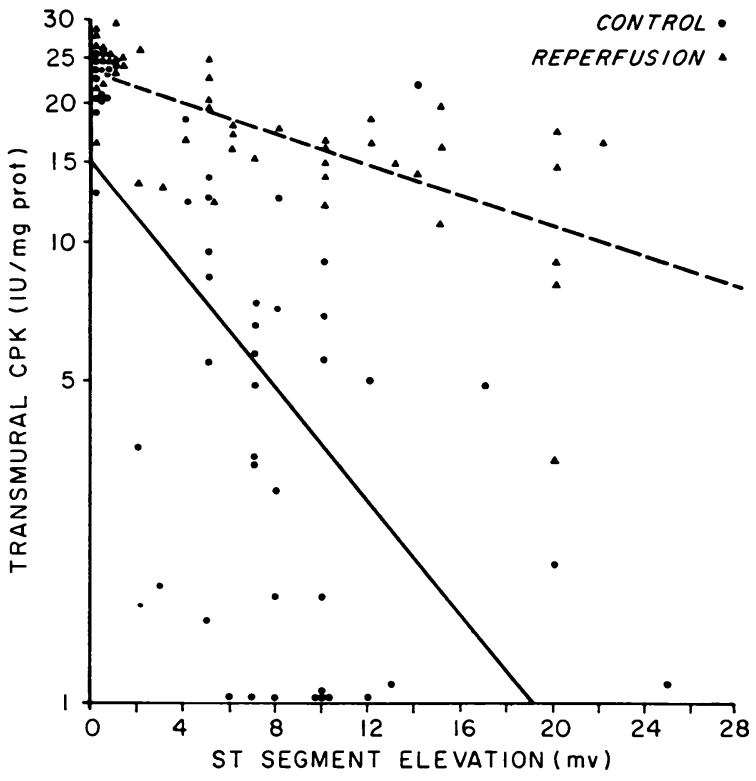

FIGURE 6 Relationship between ST segment elevation 15 min after occlusion and CPK activity (expressed on a logarithmic scale) obtained at the same site 1 wk later. Controls, solid lower line $(\log \mathrm{CPK}=0.06127 \mathrm{ST}+1.17$; $r=0.66 ; 7$ dogs, 56 biopsies) ; closed circles represent individual control samples. Reperfused hearts, broken upper line $(\log \mathrm{CPK}=-0.01658 \mathrm{ST}+1.36 ; r=0.69 ; 7$ dogs, 46 biopsies); triangles represent individual samples from reperfused hearts.

and Savranoglu, Boucek, and Casten (12) reported a rise in coronary sinus GOT after coronary artery occlusion; this elevation was persistent if the occlusion was continued to $60 \mathrm{~min}$, but attenuated when the coronary obstruction was released at $40 \mathrm{~min}$.

Detailed information concerning the acute structural alterations which follow coronary artery occlusion have been summarized by several investigators (13-15).

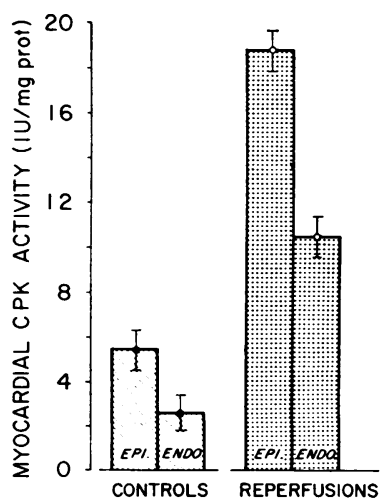

FIGURE 7 Relationship between CPK activity in epicardial (epi.) and endocardial (endo.) samples, taken from the area of initial acute injury in seven control and seven reperfused animals. 
Such alterations include rapid glycogen depletion, early influx of fluid into the cell producing clear spaces and cellular swelling. Marked clumping of nucleoplasm occurs early. Later, mitochondrial swelling with shrinkage of cristae develops which gradually progresses to complete disruption of the organelle. The point of irreversible injury usually is considered to occur when the biochemical processes of energy production can no longer maintain cellular integrity at a time between 20 and $60 \mathrm{~min}$ after coronary occlusion $(16,17)$. Recent studies by Jennings, Herdson, and Sommers (18), for example, demonstrated marked functional changes in mitochondria damaged by $60 \mathrm{~min}$ of ischemia characterized by impairment of pyruvate metabolism, depressed capacity to metabolize succinate, and a fall in mitochondrial nitrogen content.

Because of the wide biological variation in the coronary artery anatomy and collateral circulation of the canine heart, it has been difficult to assess the extent of reversibility of cell injury after coronary occlusion $(19,20)$. However, in the present study the methods employed allowed anatomic infarct size at $1 \mathrm{wk}$ to be compared with infarct size estimated acutely in the same animal, thereby allowing each animal to serve as its own control. Our experiments indicate that a very significant reduction in the extent of myocardial tissue damage is effected by coronary artery reperfusion, the salvage of myocardial tissue confirmed both by histologic examination and assay of myocardial CPK activity. It is possible that such reductions in infarct size are to a varying degree dependent upon the availability of collateral circulation. In this study several animals from both groups were excluded from the analysis after direct electrical defibrillation, since it was not possible to determine at 1 wk how much myocardial damage might have resulted from fibrillation and the electrical countershock injury. Lack of collateral supply in these experiments might have been an important factor in producing variable damage or precipitating ventricular fibrillation, however.

The fact that tissue salvage can be achieved with coronary reperfusion after a $3 \mathrm{hr}$ period of occlusion probably can be accounted for on the basis that acute obstruction of a major coronary artery rarely produces a homogeneous myocardial infarction. With the use of histochemical techniques, Lushnikov (21) has described an intermediate ischemic zone separating normal tissue from the center of an infarct. Similar observations have been made by Cox, McLaughlin, Flowers, and Horan (22) who demonstrated that the intermediate zone continued to enlarge for a period of up to $18 \mathrm{hr}$ after coronary occlusion, after which the area of central necrosis expanded at the expense of ischemic tissue. That such marginal tissue remained viable was undoubtedly re- lated to the ability of a noncontractile or hypocontractile myocardial cell to maintain basic energy requirements in the face of a reduced oxygen supply $(23,24)$.

It may be concluded that coronary artery reperfusion after a period of $3 \mathrm{hr}$ of occlusion limits the extent of the established myocardial infarction at $1 \mathrm{wk}$ in the dog by improving oxygen supply to the zones of ischemia. From a practical point of view, these studies tend to support a possible place for direct coronary artery surgery after recent myocardial infarction. However, important species differences could limit the direct extension of these studies to the clinical setting since in man there is usually evidence of diffuse coronary artery disease. The maximum time interval at which injury to cells may remain reversible has not yet been determined, but some evidence suggests that it may be as long as $18 \mathrm{hr}$ after infarction (22). Further studies to examine the time constraints for tissue salvage and maintenance of vascular integrity currently are underway.

\section{ACKNOWLEDGMENTS}

We thank Miss Lana Nimmo, Mrs. Linda Bundy, and Mr. Richard Pavelec for technical assistance.

This work was supported by the National Heart and Lung Institute, Myocardial Infarction Research Unit Contract No. $\mathrm{PH}-43-68-1332$.

\section{REFERENCES}

1. Braunwald, E. 1971. Control of myocardial oxygen consumption. Physiologic and clinical considerations. Am. J. Cardiol. $27: 416$.

2. Maroko, P. R., J. K. Kjekshus, B. E. Sobel, T. Watanabe, J. W. Covell, J. Ross, Jr., and E. Braunwald. 1971. Factors influencing infarct size following experimental coronary artery occlusions. Circulation. 43: 67.

3. Favaloro, R. G., D. B. Effler, C. Cheanvechai, R. A. Quint, and F. M. Sones, Jr. 1971. Acute coronary insufficiency (impending myocardial infarction and myocardial infarction). Surgical treatment by the saphenous vein graft technique. Am. J. Cardiol. 28: 598.

4. Lambert, C. J., M. Adam, G. F. Geisler, E. Verzosa, M. Nazarian, and B. F. Mitchel, Jr. 1971. Emergency myocardial revascularization for impending infarctions and arrhythmias. J. Thorac. Cardiovasc. Surg. 62: 522.

5. Maroko, P. R., P. Libby, W. R. Ginks, W. E. Shell, and J. Ross, Jr. 1972. Coronary artery reperfusion. I. Early effects on myocardial contractility and myocardial necrosis. J. Clin. Invest. 51: 2710.

6. Kjekshus, J. K., and B. E. Sobel. 1970. Depressed myocardial creatine phosphokinase activity following experimental myocardial infarction in rabbit. Circ. Res. 27: 403 .

7. Blumgart, H. L., D. R. Gilligan, and M. J. Schlesinger. 1941. Experimental studies on the effect of temporary occlusion of coronary arteries. II. The production of myocardial infarction. Am. Heart J. 22: 374.

8. Yabuki, S., G. Blanco, J. E. Imbriglia, L. Bentivoglio, and C. P. Bailey. 1959. Time studies of acute reversible coronary occlusions in dogs. J. Thorac. Cardiovasc. Surg. 38: 40. 
9. Fischer, S. III, and W. S. Edwards. 1963. Tissue necrosis after temporary coronary artery occlusion. Am. Surg. 29 : 617.

10. Sommers, H. M., and R. B. Jennings. 1964. Experimental acute myocardial infarction. Histological and histochemical studies of early myocardial infarcts induced by temporary or permanent occlusion of a coronary artery. Lab. Invest. 13: 1491.

11. Jennings, R. B., J. P. Kaltenbach, and G. W. Smetters. 1957. Enzymatic changes in acute myocardial ischemic injury. Glutamic oxaloacetic transaminase, lactic dehydrogenase, and succinic dehydrogenase. Arch. Pathol. 64: 10.

12. Savranoglu, N., R. J. Boucek, and G. G. Casten. 1959. The extent of reversibility of myocardial ischemia in dogs. Am. Heart J. 58: 726.

13. Brachfeld, N. 1969. Maintenance of cell viability. $C_{i r}$ culation. 40(Suppl. 4) : 202.

14. Caulfield, J., and B. Klionsky. 1959. Myocardial ischemia and early infarction: an electron microscopic study. Am. J. Pathol. 35: 489.

15. Judah, J. D., K. Ahmed, and A. E. M. McLean. 1965. Pathogenesis of cell necrosis. Fed. Proc. 24: 1217.

16. Lowry, O. H., D. R. Gilligan and A. B. Hastings. 1942. Histochemical changes in the myocardium of dogs following experimental temporary coronary arterial occlusion. Am. J. Phy'siol. 136: 474.
17. Shnitka, T. K., and M. M. Nachlas. 1963. Histochemical alterations in ischemic heart muscle and early myocardial infarction. Am. J. Pathol. 42: 507.

18. Jennings, R. B., P. B. Herdson, and H. M. Sommers. 1969. Structural and functional abnormalities in mitochondria isolated from ischemic dog myocardium. Lab. Invest. 20: 548.

19. Nachlas, M. M., and M. P. Siedband. 1967. The influence of diastolic augmentation on infarct size following coronary artery ligation. J. Thorac. Cardiovasc. Surg. 53: 698.

20. Maroko, P. R., E. F. Bernstein, P. Libby, G. A. DeLaria, J. W. Covell, J. Ross, Jr., and E. Braunwald. 1972. The effects of intra-aortic balloon counterpulsation on the severity of myocardial ischemic injury following acute coronary occlusion. Circulation. 45: 1150.

21. Lushnikov, E. F. 1963. Histochemical study of experimentally produced myocardial infarction. Fed. Proc. 22 (Translation Suppl.) : 906.

22. Cox, J. L., V. W. McLaughlin, N. C. Flowers, and L. G. Horan. 1968. The ischemic zone surrounding acute myocardial infarction. Its morphology as detected by dehydrogenase staining. Am. Heart J. 76: 650 .

23. Edwards, J. E. 1969. What is myocardial infarction? Circulation. 40(Suppl. 4) : 5.

24. McKeever, W. P., D. E. Gregg, and P. C. Canney. 1958. Oxygen uptake of the nonworking left ventricle. Circ. Res. 6: 612. 